\title{
Trânsito religioso como condição exodal Itinerário religioso em A Eternidade e o Desejo de Inês Pedrosa
}

Alessandro Rocha

\section{Resumo}

O presente artigo trata do trânsito religioso como condição existencial a partir da compreensão da literatura como lugar de revelação e como espaço de investigação do fenômeno religioso. Faz isso a partir da obra A Eternidade e o Desejo de Inês Pedrosa. $O$ texto explora a passagem da condição existencial chamada mesmidade à condição exodal conhecida como ipseidade.

Palavras-chave: Teologia/Literatura, Trânsito Religioso, Condição Exodal.

\begin{abstract}
This article deals with the religious transit as existential condition from the understanding of literature as the place of revelation and as research area of the religious phenomenon. Does this from work to Eternity and the Desire of Inês Pedrosa. The text explores the passage of existential condition called mesmidade to exodal condition known as Ipseidade.
\end{abstract}

Keywords: Theology/Literature, Religious Transit, Exodal Condition. 


\section{Introdução}

"Ouvir a divindade onde quer que ela esteja". Esta é a resposta que uma Ialorixá dá a Clara - personagem central do romance A Eternidade e o Desejo - diante da pergunta se ela ia à Igreja. A partir de tal romance exploraremos o trânsito religioso como expressão da condição exodal que o homo religiosus é capaz de experimentar. Pensar o trânsito religioso não em perspectivas sociológicas, mas fenomenológicas, é o desafio principal a ser explorado. Isso se fará no diálogo criativo entre a Teologia e a Literatura.

O tema do trânsito religioso tem sido largamente explorado, sobretudo no âmbito das ciências sociais, mas é quase sempre desprezada a dimensão existencial dos sujeitos em trânsito perdendo dessa forma a possibilidade de valorização das novas experiências religiosas realizadas por homens e mulheres. Deslocar a investigação dessa questão para a dimensão da fenomenologia é priorizar a narrativa que o sujeito religioso pode dar sobre sua mesma experiência. Aqui queremos privilegiar a narrativa literária de Clara em seu trânsito, ou ainda, em seu êxodo.

Para tanto percorreremos um itinerário que nos levará as seguintes estações: a literatura como lugar de revelação e, por isso, como espaço de investigação do fenômeno religioso; a passagem da condição existencial marcada pela angústia e desespero própria da dimensão humana chamada mesmidade à condição exodal marcada pela passagem que as pessoas fazem ao longo da vida chamada de ipseidade; e, por fim, a condição exodal investigada na obra A Eternidade e o Desejo.

\section{A literatura como locus de revelação}

A literatura como campo de estudo da religião é uma realidade no diálogo teologia/literatura. A consideração da literatura como campo de estudos dos diversos fenômenos sociais - dentre os quais destacamos aqui o religioso - tem haver com as discussões sobre a natureza da literatura e sua intencionalidade expressiva. Tomada exclusivamente em sua dimensão ficcional a literatura estaria impedida de apresentar-se como lugar de teorização da realidade. Contudo, compreendida como meta-linguagem, como expressão da condição humana em linguagem ficcional, ela se torna um espaço privilegiado para a compreensão do humano em suas diversas interações com a realidade. 
Perceber e teorizar a literatura como campo de estudo da multiplicidade de fenômenos humanos - e do religioso em especial - já é um dado importante, contudo pretendemos mais, queremos dizer que a literatura vê um locus de revelação. Para isso pressupomos como ponto de partida teológico a tese da revelação como maiêutica histórica ${ }^{1}$. Isso nos leva à máxima de que toda realidade grávida de PALAVRA fundamental.

A literatura é locus de revelação, contudo o olhar lançado sobre ela permitirá ou não ver a epifania que dela emerge. São conhecidas as máximas A Bíblia é a Palavra de Deus (onde só na letra da Escritura há revelação) e A Bíblia se torna a Palavra de Deus (onde a Escritura pode ou não tornar-se a Palavra de Deus). Em ambas o acento encontra-se na Escritura. Somente superando essa verbalização da revelação é que se pode abrir a percepção da revelação para outros locus, inclusive a literatura.

Para ilustrar essas duas possibilidades (revelação estrita na Escritura e revelação em outros locus) propomos duas hermenêuticas de acesso a palavra revelada nas escrituras (teológicas e literárias): a que vem da condição existencial e a que vem da condição exodal.

\section{Condição exodal ou ipseidade como forma de ser no mundo}

Inspiramo-nos aqui no fenômeno existencial - místico e/ou literário conhecido como êxodo. Isto é, na passagem ou mudança que as pessoas fazem ao longo de suas vidas. Passagem de uma condição a outra, de um lugar existencial a outro, de uma pertença religiosa a outra. Essa mudança transforma alguém de uma existência que poderia ser nomeada de mesmidade a outra identificada por ipseidade.

Por mesmidade compreende-se a vida enclausura nas experiências traumáticas e limitadoras de novas circunstâncias e possibilidades de transcendência. Já por ipseidade entende-se a existência voltada para superação das ataduras que amarram a vida nas mais diversas situações. Sair da mesmidade à ipseidade é de fato um êxodo.

No caso da obra A Eternidade e o Desejo encontramos tal passagem como um fio condutor em toda a narrativa. Clara faz seu êxodo - ou êxodos como

\footnotetext{
${ }^{1}$ Para maiores aprofundamentos nas questões relacionadas ao tema da revelação como maiêutica históricas e suas implicações para o diálogo entre teologia e literatura ver ROCHA, Alessandro. Experiência e discernimento. Recepção da palavra numa cultura pós-moderna. São Paulo: Fonte Editorial, 2010.
} 
veremos -, ela faz sua peregrinação da mesmidade à ipseidade. Do ponto de vista da estrutura narrativa da obra há uma teleologia: a superação da angústia e do desespero que afligem o coração (suas paixões), a mente (sua crise intelectual) e a alma (a experiência religiosa) de Clara.

A estrutura fundamental da condição exodal que enxergamos em Clara é marcada pelas seguintes etapas: situação, peregrinação, superação. A situação é a condição de angústia e desespero que Clara viva em Portugal; a peregrinação é o caminho feito (em duas etapas) para o Brasil e os encontros e desencontros que ela experimenta; a superação é o conjunto de encontros que Clara vivencia (encontros afetivos e espirituais).

\section{A condição exodal como transfundo de "A eternidade e o desejo"}

Escrito em 2007 pela portuguesa Inês Pedrosa, A Eternidade e o Desejo narra a dinâmica do "Êxodo" de Clara, professora de literatura que vive entre os amores de Antônio Vieira e as saudades de Antônio, o soteropolitano com quem teve uma fugaz relação em Portugal. Depois de Antônio retornar ao Brasil, Clara vai ao seu encontro em Salvador onde acaba ficando cega por um tiro que era para seu amado. Ferida retorna a Portugal de onde regressaria ao Brasil anos depois, aí inicia-se seu êxodo.

A caminho da Bahia com Sebastião, aquele que a ama sem ser correspondido, descobrindo que seu amado Antônio está morto, Clara sai de sua situação exodal de angústia e desespero iniciando uma peregrinação guiada por seu padre Antônio Vieira, até sua baiana Canaã, que ela encontraria nos braços de Marcos e no terreiro de Candomblé.

Ainda em Portugal Clara recebe em sonho uma "revelação" daquilo que seria seu itinerário exodal. Ela narra tal hierofania com as seguintes palavras:

A noite passada sonhei que voltava à Bahia. $\mathrm{O}$ sol atacava a pique, e eu andava de igreja em igreja a procura de alguém que não conseguia encontrar. Na rua a força do sol impedia-me de ver, nas igrejas ficava atordoada com o excesso de turistas e talha dourada. Queria gritar, mas não conseguia. Dizes-me que é uma sensação muito comum, nos sonhos. Mas eu creio que já não posso voltar a ser uma pessoa muito comum².

Guiando-se por tal hierofania Clara experimentaria dois êxodos: primeiro, o que a levará da atrofia do coração lusitano à paixão da carne baiana. O segundo, o que a conduzirá da clausura e negação do cristianismo à libertação experimen-

${ }^{2}$ PEDROSA, Inês. A eternidade e o desejo. Rio de Janeiro: Objetiva, 2008. p. 13. 
tada no Candomblé. Ambos os êxodos tem como mentor e guia o Padre Antônio Vieira, que costura todo o romance A Eternidade e o Desejo. Clara encontra as forças para sua peregrinação em várias palavras de seu Padre Antônio, como por exemplo: "O coração, os pés, as mãos, as asas, tudo vem da cabeça, que é o molde da própria fantasia. Se esta for de homem, as ações serão racionais; se de águia, altivas; se de leão, generosas; se de bois, vis"3.

Clara vem ao Brasil, para terras baianas, para fazer a cabeça, ou ainda, para re-fazer a cabeça e o coração. Nesse caminho ela experimentará seu primeiro êxodo: da atrofia do coração lusitano à paixão da carne baiana.

Som e sentido, continente e conteúdo dilacerando-se, hoje, como sempre, até que nada reste sobre a superfície hiperbólica da realidade. Dizes que aquilo que eu chamo de estatuto pode também chamar-se ânsia de eternidade. Mas eu vejo tão pouca eternidade nos sonhos das pessoas, Sebastião. A eternidade que somos conduzidos a aspirar é a da juventude - o lugar mais rápido, inseguro e variável da existência humana. O lugar do querer ser. Não vês o contra-senso que isto representa? A violência? A prisão?

Não, não vês, como eu não via. Pertencer a um país que de antigo se tornou velho também não ajuda a ver. Só através dos olhos desse Antônio que veio do Brasil eu comecei a ver. Nos olhos dele aprendi a lei Vieira, como no seu corpo aprendi a saborear o desejo infinito, o desejo como experiência da eternidade. Para essa experiência não tenho palavras. Nem sequer silêncio. Dessa experiência, sobrou-me o que sou ${ }^{4}$.

Depois de ter experimentado a eternidade nos contornos do desejo que nutria por Antônio e, de ter se tornado naquilo em que se transformou Clara experimentou uma escuridão sem fim - tanto de seus olhos quanto de seu coração e alma. Foi em meio a esse deserto noturno sem fim que Clara experimentou ser conduzida pelas colunas de nuvens constituídas pelas palavras de Vieira e alimentada pelo maná dos sermões de seu Padre. Foi ele que disse a ela o seguinte: "que coisa é a conversão de uma alma senão entrar um homem dentro em si, e ver-se a si mesmo?"'. Claro pode encontrar em sua escuridão desértica o útero para uma nova existência.

Tal caminho exodal levou Clara a desatrofiar seu luso coração. Clara clareou-se por dentro, lá onde é mais difícil as cores chegarem. Mas não só as cores

\footnotetext{
${ }^{3}$ Ibid., p. 23.

${ }^{4}$ Ibid., p. 26.

${ }^{5}$ Ibid., p. 147.
} 
chegaram no deserto Clarisso, também os cheiros, principalmente os cheiros de seu novo amado e, com ele o leite e o mel da nova terra, da Canaã baiana.

Preciso deste cheiro. Do cheiro a mar, bulício, perigo e ousadia que não encontro em Portugal. $O$ cheiro a corpos que se mostram - o cheiro a carne a sexo, à mistura de raças. O Brasil tem um odor à sobrevivência pura que me apaixona; não há nada que mate esta terra - talvez seja precisamente isto que a impede de se tornar uma superpotência do mundo e talvez seja também isso o que faz dela, estranhamente, uma referência do mundo. O Ocidente como transcendência das identidades culturais fixas, como possibilidade de superação das fronteiras da identidade, é no Brasil que o encontro. Aqui, a humanidade particular é sempre maior do que o Estado, e se isso representa coisas terríveis, no gráfico da pobreza e da injustiça, sinaliza também, ainda que de forma obscura, a possibilidade de um outro caminho, de uma outra liberdade ${ }^{6}$.

$\mathrm{Na}$ terra brasilis Clara encontra a liberdade de seu coração, liberdade não como conceito que se apreende em manuais acadêmicos - coisa que ela conhecia bem em seu Portugal -, mas como experiência concreta e por isso contraditória. Ela continua sua declaração de liberdade:

Sinto-me mais viva, aqui, onde quase morri, do que no Portugalinho que esconjura o mar da morte no charco das maleitas, o Portugalinho do cá vamos andando, quando mal nunca pior, da inveja pequenina administrativamente organizada. Dirás que exagero, e podes dizer o que quiseres, e ter até muita razão. Sucede é que a razão já não me basta - aliás, não creio que basta a ninguém. À terra que me dá a vida não posso oferecer menos do que a minha vida ${ }^{7}$.

Além da dureza do coração empedernido pela frieza acadêmica e pelo amor morto, Clara tinha a vida marcada por uma experiência religiosa jurídica e extremamente infértil. Exatamente nesse segundo aspecto é que se dá sua segunda conversão: da clausura e negação do cristianismo à libertação experimentada no Candomblé. Sobre sua experiência com o catolicismo português Clara, dialogando com seu Padre Vieira, afirma o seguinte:

O teu Deus estourou, Vieira - Jeová, ou Alá, ou como quer que se the chame, consumei-se nas fogueiras da Inquisição, nas câmaras de tortura e morte de todos os séculos, explode ainda agora nos corpos muito jovens

\footnotetext{
${ }^{6}$ Ibid., p. 154.

7 Ibid.
} 
dos bombistas suicidas. O Deus dos fiéis e dos infiéis serviu-te e ti, que soubeste amaciá-lo nos veludos do teu coração, afeiçoá-lo a essa manha portuguesa que, nas aflições, se disfarça com os nós da consolação. $\mathrm{O}$ teu Deus marinheiro, feito do braço dos Lusíadas e de uma justiça de tenças, está morto nos braços dos homens que em nome dele ainda matam, vive apenas no sopro dos teus textos que transporto sobre o mar - o teu mar, que já ninguém cruza, nesta civilização do ar .

O segundo êxodo de Clara a leva das garras de um Deus morto e sanguinário à festa sensorial dos orixás, e isso se dá pela pena de Antônio Vieira. A ela ele diz: "O sensível, o imaginário, o existente e o possível, o finito e o infinito, tudo enche, tudo inunda, por tudo se estende, e até onde? Até onde não há onde, sem termo, sem limite, sem horizonte, sem fim, e, por isso, incapaz de circunferência". É essa a experiência que Clara deseja, é esse o Deus que seu coração anseia.

Oxalá Oxalufam está a baixar sobre Marcos. Como é que eu sei, Sebastião? Vejo Oxalufam [...] Vejo-o, Sebastião, na minha névoa vejo um velho saltando sobre um corpo de homem jovem [...] Não precisas de me dizer, Sebastião, vejo. Vejo os espíritos, muito nítidos, descendo sobre corpos esfumados de mulheres. Várias mãe-de-santos rodopiam sobre si mesmas, bailarinas hipnotizadas, com olhos vazios ${ }^{10}$.

A insistência em dizer que viu choca com sua condição de cega. Clara vê, ela vê o que seu coração não via, ela vê o que o Deus morto já não revelava mais, ela vê! E quando inquirida pelos efeitos daquilo que viu só pode dizer: "Perguntas-me se estou bem, nunca estive tão bem, foi o abraço daquela mãe-de-santo ${ }^{11}$ ". Será essa mesma mãe-de-santo quem a ajudará a discernir sua chegada à terra prometida, ao término de seu êxodo.

- Dona. Pelas chagas do senhor Jesus Crucificado que nesta casa escura represento, escute o eu tenho pra lhe falar, e não é muito, não. Não faça mais turismo, não. O Português é que nem essas igrejas barrocas que a mão da gente fez a mandado dele: branco liso por fora, e todo emaranhado

\footnotetext{
${ }^{8}$ Ibid., p. 95.

${ }^{9}$ Ibid., p. 75.

${ }^{10}$ Ibid.

${ }^{11}$ Ibid., p. 76.
} 
lá pelos interiores. Em vez de colocar a vaidade no liso, coloca nessa barbaridade de ouros, e fica fácil de pegar por espírito ruim. No frio dessas igrejas não tem Deus nosso senhor nem seus santos nem orixás nem salvação nenhuma. Só o sofrimento dos negros milhões de vezes pregados na cruz onde o Cristo branco sofreu uma vez. Não precisa procurar mais, não. Seu destino era a Bahia, dona, e no seu destino a dona já está ${ }^{12}$

\section{Conclusão}

Numa dinâmica dialógica onde a literatura é assumida como um lugar de revelação percorremos a narrativa notável de A Eternidade e o Desejo de Inês Pedrosa. Percorremos junto com Clara seu êxodo que a levou a "Canaã" soteropolitana, terra que mana leite e mel, o leite do amor e o mel dos orixás. Ambos deram a Clara um coração livro livre e uma alma restaurada.

A questão fundamental desse ensaio, porém, é a afirmação do diálogo teologia/literatura como uma renovada possibilidade para o discurso teológico e os estudos literários. Além disso, vale a pena ressaltar também os traços metodológicos oferecidos para o diálogo interdisciplinar.

\section{Referências Bibliográficas}

PEDROSA, Inês. A eternidade e o desejo. Rio de Janeiro: Objetiva, 2008.

ROCHA, Alessandro. Experiência e discernimento. Recepção da palavra numa cultura pós-moderna. São Paulo: Fonte Editorial, 2010.

Alessandro Rocha
Pós-Doutor em Letras e Doutor em Teologia pela PUC-Rio,
Pesquisador da Cátedra UNESCO de Leitura da PUC-Rio,
Secretário da Associação Latino Americana de Literatura e Teologia (ALALITE),
Coordenador do GT Arte, Literatura e Religião da SOTER.

Artigo Recebido em 22/08/2011

Artigo Aprovado em 10/01/2012

${ }^{12}$ Ibid., p. 107. 